\title{
Selected Bioremediation Techniques in Polluted Tropical Soils
}

\author{
Emmanuel Uzoma Onweremadu \\ Additional information is available at the end of the chapter \\ http://dx.doi.org/10.5772/58381
}

\section{Introduction}

Ecosystems are regularly confronted with natural environmental variations and disturbances over time and geographic space. A disturbance is any process that removes biomass from a community, such as fire, flood, drought, or predation. Disturbances occur over vastly different ranges in terms of magnitudes as well as distances and time periods (Levin, 1992) and are both the cause and product of natural fluctuations in death rates, species assemblages, and biomass densities within an ecological community. These disturbances create places of renewal where new directions emerge out of the patchwork of natural experimentation and opportunity implying a good measure of ecological resilience is a cornerstone theory in ecosystem (Folke, et al., 2004). One of such disturbances is pollution which alters ecological balance.

Intense industrial activity and urbanization in recent times, especially in developing countries, have led to serious environmental pollution, resulting in a large number and variety of contaminated sites which became a threat to the local ecosystems. In all these, natural resources such as soils, water, air and vegetation are adversely affected.

Industrial revolution gave birth to environmental pollution which continued till today. It was a revolution that led to the emergence of great factories and consumption of immense quantities of fossil fuels which was associated with an unprecedented rise in air pollution and large volume of industrial chemical discharges. This was added to the growing population with a load of untreated human waste. The Second World War made pollution to become a popular issue due to radioactive fallout from atomic warfare and testing. Pollution began to draw major public attention with the emergence of cities and megacities associated with a stockpile of refuse and characterized by substantial output of sewage and particulate matter. 
Pollution defines the introduction of harmful substances often referred to as contaminants into the natural environment that cause adverse change. The term contamination is in some cases used interchangeably with pollution in environmental chemistry, where the main interest is the harm done on a large scale to humans or to organisms or environments that are important to human beings. Common soil contaminants include chlorinated hydrocarbons, heavy metals such as chromium, cadmium-found in rechargeable batteries, and lead-found in lead paint, aviation fuel and still in some countries, gasoline, zinc, arsenic and benzene. Recycling industrial byproducts into fertilizer may result in the contamination of soils with various metals. Ordinary municipal landfills are the source of many chemical substances entering the soil environment and often reaching groundwater, emanating from the wide variety of refuse.

In the case of the term contamination, it is the presence of a minor and unwanted constituent in a material, in a physical body or in the natural environment. In chemistry, contamination usually refers to a single constituent, but in specialized fields the term can also mean chemical mixtures, even up to the level of cellular materials.

Pollution may take various forms including discharge of deleterious chemical substances on natural substances. Pollution can be point source or nonpoint source pollution.

Sometimes pollution takes the form of harmful energy such as noise, heat or light. Generally speaking, foreign substances and energies which contaminate natural resources are referred to as pollutants. Substances contain some level of impurity; and this may become an issue if the impure chemical is mixed with other chemicals or mixtures and causes additional chemical reactions. Sometimes, the additional chemical reactions are beneficial, in which case the label 'contaminant' is replaced with reactant or catalyst. When additional reactions are detrimental, other terms such as toxin or poison depending on the chemistry involved are used. However, if no remedial action is undertaken, the availability of arable land for cultivation will decrease, because of stricter environmental laws limiting food production on contaminated lands. Inorganic and organic contaminants typically found in urban areas are heavy metals and petroleum-derived products. The presence of both types of contaminants on the same site presents technical and economic challenges for decontamination strategies. There have also been some unusual releases of polychlorinated dibenzodioxins, commonly called dioxins for simplicity.

In Nigeria, there is paucity of soil information leading to several forms of soil degradations. Except in recent times environmental impact assessments (EIAs) are rarely conducted on natural resources before embarking on major projects. The EIAs are often not backed up with necessary implementation legislations. Mineral exploration and exploitation as well as various construction activities are known to have negative impact on surface and subsurface soils, surface and groundwater, rocks and rocklike minerals, atmospheric resources, vegetation and wildlife.

Available soil data are not problem-solving (Lal and Ragland,1993).Non-use of soil survey data and information has led to soil and soil-related environmental problems such as nutrient depletion, nutrient imbalances, multiple nutrient deficiencies, nutrient toxicity, general decline in soil quality and yield decline. The situation is often aggravated by socioeconomic pressures 
mainly resulting from poverty and inability to afford relevant inputs of agricultural production. Sound characterization and classification of soils based on quality and proper presentation of such information in user-friendly form is a necessary adjunct in sustained use of soils. Again, soil quality data will go a long way in promoting bio-safety of farm products for both local consumption and their internationalization.

Primarily, this paper is aimed at reviewing crude oil and non-crude oil polluted soils of tropical soils with particular emphasis on Nigeria. Specifically, some biotechnological methods are suggested for the amelioration of contaminated soils. A good knowledge of status and distribution of polluted soils will go a long way in assisting in the production of land use maps which will facilitate policy and legislations on soil and soil-related natural resources. Land use maps derived from soil survey and land evaluation are useful in soil management as well as in vulnerability and risk assessments. This is true as soil quality problems vary requiring different remediation strategies to overcome.

Remediation deals with the removal of pollutants or contaminants from natural resources. The affected natural resources may include soil, groundwater, surface water sediment, vegetation, rock minerals, wildlife and air. A major aim of remediation is the recovery and general protection of human health and the environment. Sometimes, remediation is done in places intended for redevelopment. Remediation goes with an array of regulatory requirements, and its assessments are based on human health and ecological risks.

Several approaches are used in the remediation of polluted soils, ranging from biological, chemical and engineering techniques. Sometimes, it may require a combination of organic and inorganic strategies. For instance the Neapolitan yellow tuff (NYT) was utilized as a component of an organo-mineral sorbent/exchanger soil conditioner with pellet manure (NYT/PM) to reduce the mobility of $\mathrm{Cd}$ and $\mathrm{Pb}$ and recover plant performance in heavily polluted soils from illegal dumps near Santa Maria La Fossa (Lower Volturno river basin, Campania Region, southern Italy). Pot experiments were performed by adding the NYT/PM mixture $(1: 1, \mathrm{w} / \mathrm{w})$ to polluted soil at the rates of $0 \%, 25 \%, 50 \%$ or $75 \%(\mathrm{w} / \mathrm{w})$. Wheat (Triticum aestivum) was used as the test plant. The addition of organo-zeolite NYT/PM mixture significantly reduced the DTPA (diethylene-triamine-pentaacetic acid)-extractable $\mathrm{Cd}$ and $\mathrm{Pb}$ from 1.01 and $97.5 \mathrm{mg} \mathrm{kg}^{-1}$ in the polluted soil, to 0.14 and $11.6 \mathrm{mg} \mathrm{kg}^{-1}$, respectively, in the soil amended with $75 \%$ NYT/PM. The best plant response was observed in amended soil systems treated with 25\% NYT/PM, whereas larger additions induced plant toxicities due to increased soil salinity.

When a soil on site is found to be contaminated to a depth of several metres and construction work needs to get started in a few months' time, soil replacement is the fastest remedy. However, some of the contaminated areas can be restored by combining modern and age-old methods. This is where plants and their microbial partners may enter the picture now and in the future. This because heavy metals in soils with residence times of thousands of years present numerous health dangers to higher organisms (Garbisu and Alkorta,2001). They are also known to decrease plant growth, ground cover and have a negative impact on soil microflora (McGrath et al.,2001). There is increasing and widespread interest in the maintenance of soil quality and remediation strategies for management of soils contaminated with 
trace metals, metalloids or organic pollutants. Heavy metals are deposited in soils by atmospheric input and the use of mineral fertilizers or compost, and sewage sludge disposal. Conventional remediation methods usually involve excavation and removal of contaminated soil layer, physical stabilization and washing of contaminated soils with strong acids or HM chelators (Steele and Pichtel,1998). Bioremediation, that is. the use of living organisms to manage or remediate polluted soils, is an emerging technology. It is defined as the elimination, attenuation or transformation of polluting or contaminating substances by the use of biological processes.

It is no new discovery that many plant species can grow in soils contaminated by various pollutants. Some species can even sequester or decompose contaminants. Soil and plant microbes help plants survive in harsh conditions.

Bioremediation includes the productive use of biodegradative processes in the elimination or detoxification of pollutants that have found their way into the environment, especially where such pollutants are capable of threatening public health. Some of the methods are ex situ while others are in situ. The ex situ bioremediation techniques involve the excavation or removal of soil from ground. A good number of in situ bioremediation techniques are generally the most desirable options due to cheapness and less disturbances since they provide the services in place avoiding excavation and transport of contaminants. Processes include phytoremediation, phytostabilization, phytotransformation, phytoextraction, rhizofiltration and phytoscreening.

Phytoremediation involves the treatment of polluted natural resource through the use of plants that mitigate the problem without the need to excavate the contaminant material and dispose of it elsewhere. The use of plants in remediation has been growing rapidly in popularity worldwide for the last twenty years or so. Phytoremediation may be defined as use of vegetation to contain, sequester, remove, or degrade organic and inorganic contaminants in soils, sediments, surface water and groundwater. Phytoremediation is a technology that uses plants to remove contaminants from soil and water (Raskin and Ensley,2000). The basic idea that plant can be used for environmental remediation is very old and cannot be traced to any particular source. However, a series of fascinating scientific discoveries combined with an interdisciplinary research approach have allowed the development of this idea into a promising, cost-effective, and environmental friendly technology.

Certain plants and microorganisms are able to precipitate metal compounds in the rhizosphere. Efficacy was shown by the use of lead pyromorphite (Cotter-Howells et al.,1999), as phytoremediation may provide an effective means to reduce metal toxicity as well as metal mobility ( Cotter-Howells and Caporn,1996). This is referred to as phytoimmobilisation. Although the application of microbial biotechnology has been successful with petroleumbased constituents, microbial digestion has met limited success for widespread residual organic and metals pollutants. Vegetation-based remediation shows potential for accumulating, immobilizing, and transforming a low level of persistent contaminants. We can find five types of phytoremediation techniques, classified based on the contaminant fate: phytoextraction, phytotransformation, phytostabilization, phytodegradation, rhizofiltration, even if a combination of these can be found in nature. 
Phytoremediation consists of reducing or eliminating pollutant concentrations in contaminated soils, water, or air, with plants. Selected plant species are able to contain, degrade, or eliminate metals, pesticides, solvents, explosives, crude oil and its derivatives, and various other contaminants from the media that contain them. Boyd and Javre (2001) reported phytoenrichement of soils by Sebertia acuminata in New Caledonia. In phytoremediation, the assumption is that certain plants called hyperaccumulators are able to bioaccumulate, degrade,or render harmless contaminants found in natural resources such as soils, water, and air. The maize plant (Zea mays) showed high tolerance towards $\mathrm{Cr}$ with negligible concentration in leaves (Lasat et al.,1998). A plant is said to be a hyperaccumulator if it can concentrate the pollutants in a minimum percentage which varies according to the pollutant involved. More than $1000 \mathrm{mg} / \mathrm{kg}$ of dry weight for nickel, copper, cobalt, chromium or lead; or more than $10,000 \mathrm{mg} / \mathrm{kg}$ for zinc or manganese are recommended (Baker and Brooks,1989). In addition to this, it is assumed that hyperaccumulating plants can be found thriving under very harsh conditions or under situations that are not ideal for plant growth.

Some plants are able to translocate and accumulate particular types of contaminants. Plants can be used as biosensors of subsurface contamination, thereby allowing investigators to quickly delineate contaminant plumes (Burken et al.,2011). Chlorinated solvents have been observed in tree trunks at concentrations related to groundwater concentrations (Vroblesky et al.,1998). Phytoscreening often leads to more optimized site investigations and reduce contaminated site cleanup costs. Phytoremediation has become increasingly popular and has been employed at sites with soils contaminated with lead, uranium, and arsenic and it has the advantage that environmental concerns may be treated in situ.

The technology of phytoremediation has been successfully used in the restoration of abandoned metal-mine sites, reducing the impact of sites where polychlorinated biphenyls have been dumped during manufacture and mitigation of on-going coal mine discharges.

There are a range of processes mediated by plants which are useful in soil and soil-related environmental problems. Processes include phytostabilization, phytotransformation, phytoextraction,rhizofiltration and phytoscreening.

Phytostabilization entails the reduction of the mobility of substances in the environment. This could be done by limiting the leaching of substances from the soil. Its main focus is on longterm stabilization and containment of the pollutant. Plants can reduce wind erosion; or their roots can prevent water erosion, immobilize the pollutants by adsorption or accumulation, and provide a zone around the roots where the pollutant can precipitate and stabilize. Phytostabilization focuses mainly on sequestering pollutants in soil near the roots but not in plant tissues. By this, pollutants become less bioavailable to livestock and wildlife, and human exposure is drastically reduced.

Phytoextraction is the uptake and concentration of substances from the environment into the plant biomass. The use of plants to mine toxicants is called phytomining. Phytoextraction employs metal hyperaccumulator plant species to transport high quantities of metals from soils into the harvestable parts of roots and aboveground shoots (Chaney et al.,1997). Phytoextraction is an innovation using higher plants for in situ decontamination of metal-polluted 
soils, sludges and sediments (Wenzel and Jockwer,1999). Large biomass production and high rates of metal uptake and translocation into the shoot system are critical in achieving reasonable metal extraction rates. Effective phytoextraction requires both plant genetic ability and the development of optimal agronomic management practices (Gupta and Sinha,2007). Hyper accumulators are defined as plants that contain in their tissue more than 1,000 mg kg-1 dry weight of $\mathrm{Ni}, \mathrm{Co}, \mathrm{Cu}, \mathrm{Cr}$, Pb, or more than $10,000 \mathrm{mg} \mathrm{kg}-1$ dry weight of $\mathrm{Zn}$, or $\mathrm{Mn}$ (Steele and Pichte,1998). Hyper accumulation is thought to benefit the plant by means of allelopathy, defence against herbivores, or general pathogen resistance in addition to metal tolerance (David et al.,2001). In-situ phytoextraction of $\mathrm{Ni}$ by a native population of Alyssum murale on an ultramafic site (Albania) have been reported (Bani et al.,2007). In the case of phytomining, the use of native flora (including local populations of hyperaccumulators) with limited agronomic practices (extensive phytoextraction) could be an alternative to intensively managed crops. The use of plants in remediation has been growing rapidly in popularity worldwide for the last twenty years or so. In general, this process has been tried more often for extracting heavy metals than for organics The technique of phytoextraction uses plants to remove contaminants from soils, sediments or water into harvestable plant biomass. Such organisms that absorb larger-than-normal amounts of contaminants from the soil are referred to as hyperaccumulators. Examples of hyperaccumulators are Athyrium yokoscense (Japanese false spleenwort), Avena strigosa (Brittle oat), Crotalaria juncea (Sunn hemp), Eichhornia crassipes (water hyacinth), Pistia stratiotes (water lettuce). Helianthus annuus (Sunflower), Salix viminalis (Basket willow), Lemna minor (Duckweed), Amaranthus retroflexus (Redroot Amaranth), Glomus intradices (Mycorrhizal fungus), Eragrostis bahiensis (Bahia lovegrass), Cynodon dacotylon (Bermuda grass), Festuca arundinacea (Tall fescue), Lolium perenne (Perennial ryegrass), Panicum virgatum, (Switchgrass), Phaseolus acutifolius (Tepary beans), Cocos nucifera (Coconut tree), Spirodela polyrhiza (Giant duckweed), Tagetes erecta (African-tall) and Zea mays (Maize)

In phytoremediation, plants absorb contaminants through the root system and store them in the root biomass and/or transport them up into the stems and/or leaves. A living plant may continue to absorb contaminants until it is harvested. Thereafter the process, the cleaned soil can support other vegetation with significant healthfulness.

Some transgenic plants containing genes for bacterial enzymes have been found to be effective hyperaccumulators (Meagher, 2000). Salt-tolerant plants like sugar beets are commonly used for the extraction of sodium chloride in reclaiming soils previously flooded by salt water. Sunflower (Helianthus annuus) is an effective hyperaccumulator in cleaning soils contaminated with arsenic. In general, plants with non-invasive and moisture-tolerant root systems can be planted on the embankments. Crops most commonly planted in decontamination systems in Colombia are plantain (Musa paradisiaca), papaya (Carica papaya), bore (Alocasia macrorrhiza), sugar cane (Saccharum officinarum) and nacedero tree (Trichanthera gigantea). They are commonly used for forage production in Colombia. Under local conditions it produces about 10 tons of dry matter ha/year with 18 per cent of protein in the foliage dry matter. A good number of them grow very well in the sub-Saharan Africa, therefore are suggested for phytoremediation in that region. 
There are two major forms of phytoextraction, namely assisted or natural phytoextraction. In induced or assisted phytoextraction, hyper-accumulators are cultivated for the purpose of remediation. It is associated with the use of chelators in soils to increase metal solubility or mobilization so that the plants can absorb them more easily. In natural phytoextraction, plants naturally take up the contaminants in soil unassisted. Many natural hyperaccumulators are metallophyte plants that can tolerate and incorporate high levels of toxic metals.

An advantage of phytoextraction is friendly moderate impact in the soil ecosystem. Most traditional methods commonly used for cleaning up heavy metal-contaminated soil disrupt soil structure and reduce soil productivity, but phytoextraction has the ability of cleaning up the soil without causing any kind of harm to soil quality and soil structural integrity. In addition to this, phytoextraction is cost-effective when compared with other soil remediation techniques, although it is frequently argued argued that significant effects are only achieved in the long term.

Phytotransformation describes chemical modification of environmental substances as a direct result of plant catabolic and anabolic activities. These activities lead to inactivation, degradation or immobilization. The degradation as caused by plants is referred to as phytodegradation, On the other hand, immobilization is known as phytostabilization which is a process of reducing the mobility of substances in the environment, for example, by limiting the leaching of substances from the soil.

Certain plants render organic pollutants, such as pesticides, explosives, solvents, industrial chemicals, and other xenobiotic substances non-toxic by their metabolism. Sometimes, microorganisms living in association with plant roots may metabolize these substances in soil or water. These complex and recalcitrant compounds cannot be broken down to basic molecules (water, carbon-dioxide, etc.) by plant molecules, and, hence, the term phytotransformation represents a change in chemical structure without complete breakdown of the compound. The term "Green Liver Model" is used to describe phytotransformation, as plants behave analogously to the human liver when dealing with these xenobiotic compounds or foreign compounds (Burken et al., 2004). After uptake of the xenobiotics, plant enzymes increase the polarity of the xenobiotics by adding functional groups such as hydroxyl groups (-OH).

This is known as Phase I metabolism, similar to the way that the human liver increases the polarity of drugs and foreign compounds. Whereas in the human liver enzymes such as Cytochrome P450s are responsible for the initial reactions, in plants enzymes such as nitroreductases carry out the same role.

In the second stage of phytotransformation, known as Phase II metabolism, plant biomolecules such as glucose and amino acids are added to the polarized xenobiotic to further increase the polarity (known as conjugation). This is again similar to the processes occurring in the human liver where glucuronidation (addition of glucose molecules by the UGT (e.g. UGT1A1) class of enzymes) and glutathione addition reactions occur on reactive centres of the xenobiotic.

Phase I and II reactions serve to increase the polarity and reduce the toxicity of the compounds, although many exceptions to the rule are seen. The increased polarity also allows for easy transport of the xenobiotic along aqueous channels. 
In the final stage of phytotransformation (Phase III metabolism), a sequestration of the xenobiotic occurs within the plant. The xenobiotics polymerize in a lignin-like manner and develop a complex structure that is sequestered in the plant. This ensures that the xenobiotic is safely stored, and does not affect the functioning of the plant. However, preliminary studies have shown that these plants can be toxic to small animals (such as snails), and, hence, plants involved in phytotransformation may need to be maintained in a closed enclosure.Hence, the plants reduce toxicity (with exceptions) and sequester the xenobiotics in phytotransformation. Trinitrotoluene phytotransformation has been extensively researched and a transformation pathway has been proposed (Subramanian et al.,2006).

In the case of organic pollutants, such as pesticides, explosives, solvents, industrial chemicals, and other xenobiotic substances, certain plants, such as Cannas, render these substances nontoxic by their metabolism. In other cases, microorganisms living in association with plant roots may metabolize these substances in soil or water. These complex and recalcitrant compounds cannot be broken down to basic molecules (water, carbon-dioxide, etc.) by plant molecules, and, hence, the term phytotransformation represents a change in chemical structure without complete breakdown of the compound. The mechanism is likened to the Green Liver Model which is used to describe phytotransformation, as plants behave analogously to the human liver when dealing with these foreign compound/pollutant (Burken, 2004), After uptake of the xenobiotics, plant enzymes increase the polarity of the xenobiotics by adding functional groups such as hydroxyl groups $(-\mathrm{OH})$.

This is known as Phase I metabolism, similar to the way that the human liver increases the polarity of drugs and foreign compounds. Whereas in the human liver enzymes such as Cytochrome P450s are responsible for the initial reactions, in plants enzymes such as nitroreductases carry out the same role.In the Phase II metabolism, plant biomolecules such as glucose and amino acids are added to the polarized foreign compound pollutants to further increase the polarity. This is known as conjugation and is again similar to the processes occurring in the human liver where glucuronidation and glutathione addition reactions occur on reactive centres of the xenobiotic.

Phase I and II reactions serve to increase the polarity and reduce the toxicity of the compounds, although many exceptions to the rule are seen. The increased polarity also allows for easy transport of the xenobiotic along aqueous channels.In the Phase III metabolism, the foreign pollutant compounds are a sequestered within the plant. The xenobiotics polymerize in a lignin-like manner and develop a complex structure that is sequestered in the plant where they are safely stored. However, such plants can be toxic to small animals like snails, and, hence, plants involved in phytotransformation may need to be maintained in a closed enclosure. Plants therefore reduce toxicity and sequester the xenobiotics through phytotransformation. Trinitrotoluene phytotransformation has been extensively researched and a transformation pathway has been proposed (Subramanian et al.,2006).

A significant number of organic chemicals and many inorganic ones are subject to enzymatic attack through the activities of living organisms. Efficacy of microbes in decontamination depends on some edaphic properties such as soil $\mathrm{pH}$ soil aeration, soil nutrient status, soil moisture, soil temperature, soil texture and type of heavy metal (Vidali,2001). According to 
Thapa et al. (2012,) most of modern society's environmental pollutants are included among these chemicals, and the actions of enzymes on them are usually lumped under the term biodegradation. The productive use of biodegradative processes eliminate or detoxify pollutants that have found their way into the environment and threaten public health, usually as contaminants of soil, water, or sediments is bioremediation (Thapa et al.,2012).

Some microbes can reduce activity of different types of heavy metals. Agricultural wastewater treatment can be effectively undertaken through biological processes involving the activity of microorganisms such as bacteria, algae, fungi, plants and animals (Chara et al.,1999). This they can do by their ability to convert active forms of toxic metals to inactive forms. However, choice of microbes depends on the availability of energy sources of the organisms in question. Other environmental conditions like temperatures, oxygen, moisture and the presence of hazardous contaminant contribute immensely in influencing efficacy of microbes in remediation programmes. The aerobic bacteria recognized for their degradative abilities are Pseudomonas, Alcaligenes, Sphingomonas. These microbes have often been reported to degrade pesticides and hydrocarbons, both alkanes and polyaromatic compounds. Many of these bacteria use the contaminant as the sole source of carbon and energy. The contact between the bacteria and contaminant is a precondition for degradation. Some bacteria are mobile and exhibit a chemotactic response, sensing the contaminant and moving toward it (Burken et al., 2011).

Soil fungi are very helpful in cleaning the pedosphere. The use of fungi in remediation is mycoremediation. Mycoremediation is a form of bioremediation in which fungi are used to decontaminate the area. The term mycoremediation refers specifically to the use of fungal mycelia in bioremediation. One of the primary roles of fungi in the ecosystem is decomposition, which is performed by the mycelium. The mycelium secretes extracellular enzymes and acids that break down lignin and cellulose, the two main building blocks of plant fiber. These are organic compounds composed of long chains of carbon and hydrogen, structurally similar to many organic pollutants. The key to mycoremediation is determining the right fungal species to target a specific pollutant. Certain strains have been reported to successfully degrade the nerve gases VX and sarin.

In one conducted experiment, a plot of soil contaminated with diesel oil was inoculated with mycelia of oyster mushrooms ; traditional bioremediation techniques (bacteria) were used on control plots. After four weeks, more than 95\% of many of the PAH (polycyclic aromatic hydrocarbons ) had been reduced to non-toxic components in the mycelial-inoculated plots. It appears that the natural microbial community participates with the fungi to break down contaminants, eventually into carbon dioxide and water. Wood-degrading fungi are particularly effective in breaking down aromatic pollutants (toxic components of petroleum ), as well as chlorinated compounds.

Rhizofiltration is the uptake of metals into plant roots. Mycofiltration is a similar process, using fungal mycelia to filter toxic waste and microorganisms from water in soil. Soils Arbuscular mycorrhizae (AM) are ubiquitous symbiotic associations between higher plants and soil fungi (Brown and Wilkins,1985) and their extra-radical mycelium form bridges between plant roots and soil, and mediate the transfer of various elements into plants. There is also a growing body of evidence that arbuscular mycorrhizal fungi can exert protective effects on host plants under 
conditions of soil metal contamination. Binding of metals in mycorrhizal structures and immobilization of metals in the mycorrhizosphere may contribute to the direct effects. Indirect effects may include the mycorrhizal contribution to balanced plant mineral nutrition, especially P nutrition, leading to increased plant growth and enhanced metal tolerance. It has been widely reported that ectomycorrhizal and ericoid mycorrhizal fungi can increase the tolerance of their host plants to heavy metals when the metals are present at toxic levels. The underlying mechanism is thought to be the binding capacity of fungal hyphae to metals in the roots or in the rhizosphere which immobilizes the metals in or near the roots and thus depresses their translocation to the shoots (Smith and Read, 1997). Arbuscular mycorrhizal plants may exhibit much lower shoot concentrations of $\mathrm{Zn}$ and higher plant yields than non-mycorrhizal controls, indicating a protective effect of mycorrhizas on the host plants against potential $\mathrm{Zn}$ toxicity (Diaz et al.,1996). It has been demonstrated that at high soil heavy metal concentrations, arbuscular mycorrhizal infection reduced the concentrations of $\mathrm{Zn}, \mathrm{Cd}$ and $\mathrm{Mn}$ in plant leaves (Heggo et al.,1990). Field investigations have indicated that mycorrhizal fungi can colonize plant roots extensively even in metal contaminated sites (Sambandan et al.,1992).

Phytodegradation is commonly applied as a phytoremediation measure. Phytodegradation (also rhizodegradation) is the breakdown of contaminants through the activity existing in the rhizosphere. Rhizobacteria are effective in nickel extraction (Abou-Shanab et al.,2003). It is facilitated by the presence of proteins and enzymes produced by the plants or by soil organisms such as bacteria, yeast, and fungi. Rhizodegradation is a symbiotic relationship where the plants provide nutrients necessary for the microbes to thrive, while microbes provide a healthier soil environment.

Rhizofiltration is a water remediation technique that involves the uptake of contaminants by plant roots. Rhizofiltration is used to reduce contamination in natural wetlands and estuarine areas.

Phytodegradation or rhizodegradation is the breakdown of contaminants through the activity existing in the rhizosphere due to the presence of proteins and enzymes produced by the plants or by soil organisms such as bacteria, yeast, and fungi. Rhizodegradation is a symbiotic relationship where the plants provide nutrients necessary for the microbes to thrive, while microbes provide a healthier soil environment.

Soils that have been contaminated for a long time may undergo prolonged remediation (Olson et al.,2007) and are less responsive to rhizodegradation than their freshly contaminated counterparts (Gunderson et al.,2007). There is therefore a need for enhancement of bioavailability as a key for successful biodegradation. Often times, selection and engineering of plants and microbial strains that modify solubility and transport of organic pollutants through exudation of biosurfactants become necessary and promising (Wang et al.,2007). In enhancing rhizodegradation, gene cloning of plants containing bacterial enzymes for the degradation of organic pollutants such as PCBs will be helpful in this regard. Other practices include the use of of root-colonising bacteria like Pseudomonas fluorescens expressing degradative enzymes such as ortho-monooxygenase for toluene degradation (Yee et al.,1998).In Nigeria, soils and sediments polluted with crude oil hydrocarbons are of major environmental concern on various contaminated sites. Hydrocarbon-degrading microorganisms are ubiquitously 
distributed in soils and constitute less than $1 \%$ of the total microbial communities but may increase to $10 \%$ in the presence of crude oil (Atlas,1995). However, use of fertilizers in hydrocarbon-contaminated soils act as biostimulants in such conditions. Some microbes are able to use HC as a carbon and energy source (van Hamme et al.,2003) preferentially in the absence of a readily available carbon source like labile natural organic matter. Read et al. (2003) observed increased phosphorus mobilisation due to exudation of biosurfactants by lupine (Lupinus angustifolius)

Rhizofiltration is a water remediation technique that involves the uptake of contaminants by plant roots. Rhizofiltration is used to reduce contamination in natural wetlands and estuary areas.

Bioremediation can be classified as ex situ and in situ bioremediation. The former techniques involve the excavation or removal of soil from ground. Important ex situ treatments are composting, biopiles land farming, and bioreactors. In situ is a simple technique in which contaminated soil is excavated and spread over a prepared bed and periodically tilled until pollutants are degraded. The goal is to stimulate indigenous biodegradative microorganisms and facilitate the aerobic degradation of contaminants. The practice is limited to the treatment of superficial $10-35 \mathrm{~cm}$ of soil. Since land farming has the potential to reduce monitoring and maintenance costs, as well as clean-up abilities, it has received much attention as a disposal alternative. In land farming, contaminated soils are combined with nonhazardous organic amendments such as manure or agricultural wastes. Organic materials in land farming supports the development of a rich microbial population and elevated temperature Composting is a process of piling contaminated soil organic substances such as manure or agricultural wastes. The added organic material supports the development of a rich microbial population and elevates temperature of the pile. Stimulation of microbial growth by added nutrients results in effective biodegradation in a relatively short period of time characteristic of composting. Sometimes, biopiles are used in bioremediation. A biopile is a hybrid of land farming and composting; and is used for treatment of surfaces contaminated with petroleum hydrocarbons. Biopiles are improved forms of land farming that tend to control physical losses of the contaminants through leaching and volatilization. Land farming is a method in which contaminated soil is spread over a prepared bed along with some fertilizers and occasionally rotated. It stimulates the activity of bacteria and enhances the degradation of oil. But, the use of biopiles provides a favourable environment for autochthonous aerobic and anaerobic microorganisms.

Composting is a process of piling contaminated soil organic substances such as manure or agricultural wastes. The added organic material supports the development of a rich microbial population and elevates temperature of the pile. Stimulation of microbial growth by added nutrients results in effective biodegradation in a relatively short period of time (Thapa et al., 2012).

Most in situ bioremediation techniques are generally the most desirable options due to cheapness and less disturbances since they provide the services in place avoiding excavation and transport of contaminants. This could useful in pro-poor communities common in subSaharan Africa. However, in situ remediation is among other factors governed by depth of soils for its efficacy. In many soils effective oxygen is also a prerequisite. Examples of important 
in situ bioremediation include are biosparging, bioventing, in situ biodegradation, and bioaugmentation. The Deinococcus radiodurans is used for metal remediation in radioactively polluted environments (Brim et al.,2000).

Crude oil is a mixture of thousands of varying chemical compounds. Given that composition of each type of oil is unique, there are different ways to bioremediate them using microbes and flora. Bioremediation can occur naturally or can be encourage with addition of microbes and fertilizers.

The microbes present in the soil at early stage recognize the oil and its constituents by biosurfactants and bio emulsifiers. After this, they attach themselves and use the hydrocarbon present in the petroleum as a source of energy. However, low solubility and adsorption of high molecular weight hydrocarbons can pose as a limiting factor to their availability to microorganisms. But, addition of biosurfactants enhances the solubility and removal of these contaminants. Again, rates of oil biodegradations increases with addition of biosurfactants.

Volatility, volubility, and susceptibility to biodegradation differ distinctly among constituents of crude oil. Some compounds are easily degraded, some resist degradation and some are nonbiodegradable (Mukred et al.,2008). Yet, biodegradation of different petroleum compounds occurs simultaneously but at different rates because different species of microbes preferentially attack different compounds. This scenario leads to progressive and successive disappearance of constituents of crude oil over time.

Microbes produce enzymes in the presence of carbon sources, and these enzymes are responsible for the break down of hydrocarbon molecules. Many different enzymes and metabolic pathways are involved in the degradation of hydrocarbons contained in crude oil polluted soils. It implies that complete hydrocarbon degradation requires an appropriate enzyme, unavailability of which either prevents or minimizes its breakdown.

Bioremediation has various benefits of outstanding environmental and agricultural implications.

People perceive bioremediation as an acceptable strategy for the transformation of a wide variety of pollutants, often involving recycling (Polprasert, 1989).

Byproducts from bioremediation treatment are usually harmless products. Such residues include carbon dioxide, water, and cellular biomass, implying that most hazardous contaminants can be transformed to harmless products thereby eliminating the chance of future liability associated with treatment and disposal of contaminated material.

Processes involved in bioremediation can be conducted on-site without causing a major disruption of normal activities of the ecosystem. But, this, they need to transport quantities of waste off site and the potential threats to human health and the environment that can arise during transportation are eliminated.

Bioremediation is cheap when compared with other technologies that are used for clean-up of toxic waste. Some of the contaminants are sources of energy to the soil microbes thereby sustaining microbial biodiversity. Certain bacteria are mobile and exhibit a chemotactic response, sensing the contaminant and moving toward it. 
Bioremediation was described as a strategy for integrated and sustainable development (Preston and Murgueitio, 1992). More possibilities of recycling wastes within farming systems become available as wastes from one process become inputs for another (Preston and Murgueitio 1992).

\section{Limitations of bioremediation}

1. Bioremediation is limited to those compounds that can be degraded biologically. However, not all compounds are susceptible to rapid and complete degradation. Some substrates such as straw, saw dust and maize cobs can be used to facilitate contact between soil microbes and toxicants.

2. Biological processes are often highly specific. For instance, anaerobic bacteria used for bioremediation of polychlorinated biphenyls in river sediments, dechlorination of the solvent trichloroethylene. The white rot fungus Phanaerochaete chrysosporium have the ability to degrade an extremely diverse range of persistent or toxic environmental pollutants

3. Research is needed to develop and engineer bioremediation technologies that are appropriate for sites with complex mixtures of contaminants that are not evenly dispersed in the environment.

4. Bioremediation often takes longer than other treatment options, such as excavation and removal of soil or incineration.

5. Regulatory uncertainty remains regarding acceptable performance criteria for bioremediation and there are no acceptable endpoints for bioremediation treatments. 6) There are some concerns that the products of biodegradation may be more persistent or toxic than the parent compound.

\section{Justification}

Soil pollution is widespread in Nigeria leading to varying forms of degradation. Soil pollution in Nigeria is associated with loss of bioresources especially plant materials. In reaction to this, it becomes imperative to use biological techniques in restoring and resisting further degradation.

\section{Materials and methods}

Nigeria, the most populous country in Africa, is situated on the Gulf of Guinea in West Africa with a land area of $351,649 \mathrm{sq} \mathrm{mi}(910,771 \mathrm{sq} \mathrm{km})$; and total area of 356,667 sq mi $(923,768 \mathrm{sq}$ 
$\mathrm{km}$ ). Nigerian population is estimated to be152,217,341 with a growth rate: of $1.9 \%$; Its neighbors are Benin, Niger, Cameroon, and Chad. The lower course of the Niger River flows south through the western part of the country into the Gulf of Guinea. Swamps and mangrove forests border the southern coast; while inland areas are hardwood forests. The vegetation of Nigeria northwards include derived savannah,guinea savannah,sudan savannah and sahel savannah. Seven major soil groups in Nigeria include Alfisols, Ultisols, Inceptisols, Entisols, Vertisols, Oxisols and Histosols. Arable farming is a major socioeconomic activity while crude oil prospecting is a chief source of national revenue. Oil and oil-related activities plus urban wastes constitute significant mechanism of pollution.

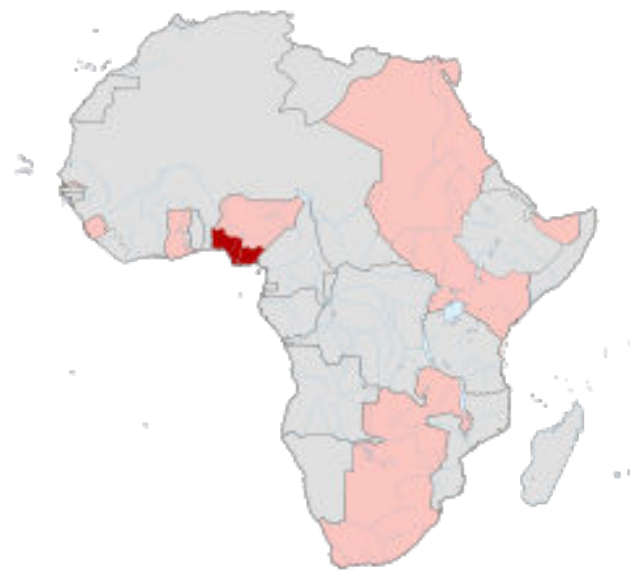

Figure 1. Location map of the study area

Soil samples were collected by random sampling in polluted soils studied. Soil samples were collected from epipedons ( $0-15 \mathrm{~cm}$ depth) only. The soil samples were sieved using 2-mm sieve before they were subjected to various laboratory analyses.

Cation exchange capacity was measured by ammonium acetate method at a pH 7 (Soil Survey Staff, 2003). Soil pH was determined using a 1:1 soil :water ratio (Soil Survey Staff, 2003). Total carbon content of soils was estimated by loss on ignition using LECO equipment (Leco Corp, St. Joseph, M. I.). Exchangeable $\mathrm{Ca}$ and $\mathrm{Mg}$ in ammonium acetate extracted solution (leachate) were estimated with atomic absorption spectrophotometer (Perkin Elmer Model) while exchangeable $\mathrm{K}$ and Na were measured by flame photometry. Total nitrogen was estimated by microkjeldahl (Bremner, 1996). Available phosphorus was obtained using Bray P No.2 method (Olsen and Sommers, 1982).

Soil heavy metals were extracted with $1 \mathrm{M}$ ammonium acetate $\left(\mathrm{NH}_{4} \mathrm{OAc}\right)$ [1:4 ratio of soil / 1 $\mathrm{M} \mathrm{NH}_{4} \mathrm{OAc}$ extraction solution : 60 minutes reaction time (Reed and Martens, 1996]. After extraction, the suspension was centrifuged at $7500 \times \mathrm{g}$ relative centrifuge force for 30 minutes and the supernatant was passed through a Whatman No.42 paper. The filter paper was allowed 
to drip dry. The metal concentrations in the supernatant after centrifugation were determined using Inductively Coupled Plasma Optical Emission Spectroscopy, IRIS N701776 (Thermo Jarrell Ash Corporation). The total petroleum hydrocarbon (TPH) was determined using Fourier Transform Infra-red spectrometry (FTIR) (QAL/AM/S 16) at wavelengths ranging from $2800-3200 \mathrm{~cm}$. The digestion and analytical procedures were checked by analysis of DOLT-3 Matrix Certified Reference Material with known concentration for heavy metals (Cantillo and Calder, 1990).

\section{Results}

Table 1 shows chemical composition of cassava sludge as opposed to compost derived from it. The result showed that cassava sludge had higher values of total carbon and total nitrogen than the compost manure formed from it.Resultantly, the C:N ratio was 17 when compared to 10 got from the compost. Values of exchangeable calcium and potassium were 9.8 and 18.3 $\mathrm{cmol} / \mathrm{kg}$, respectively in the compost manure as opposed to 9.3 and $7.4 \mathrm{cmol} / \mathrm{kg}$ in cassava sludge. Composting of cassava sludge reduced total values of heavy metals in it (Table 1). The $\mathrm{pH}_{\mathrm{KCl}}$ value of composted cassava sludge increased to 6.3 (Table 1).

\begin{tabular}{lcc}
\hline Properties & Sludge & Final Compost \\
\hline Total carbon $(\mathrm{g} / \mathrm{kg})$ & 342 & 138 \\
Total nitrogen $(\mathrm{g} / \mathrm{kg})$ & 20 & 13 \\
Carbon-nitrogen ratio & 17 & 10 \\
Exchangeable calcium $(\mathrm{cmol} / \mathrm{kg})$ & 9.3 & 9.8 \\
Exchangeable magnesium $(\mathrm{cmol} / \mathrm{kg})$ & 7.8 & 5.3 \\
Exchangeable potassium $(\mathrm{cmol} / \mathrm{kg})$ & 7.4 & 18.3 \\
Available phosphorus $(\mathrm{mg} / \mathrm{kg})$ & 2.2 & 1.5 \\
Total chromium $(\mathrm{mg} / \mathrm{kg})$ & 2.6 & 0.9 \\
Total cadmium $(\mathrm{mg} / \mathrm{kg})$ & 3.3 & 2.4 \\
Total vanadium $(\mathrm{mg} / \mathrm{kg})$ & 2.8 & 1.2 \\
Total nickel $(\mathrm{mg} / \mathrm{kg})$ & 7. & 2,3 \\
Total petroleum hydrocarbon $(\mathrm{mg} / \mathrm{kg})$ & 58.6 & 12.4 \\
pH & 4.9 & 6.3 \\
\hline
\end{tabular}

(Source: Onweremadu, 2008)

Table 1. Typical chemical characteristics of the cassava sludge and the produced compost (dry weight basis)

Certain factors influence ability of microbes to cause degradation (Table 2).Soil moisture requirement for optimum degradation of oil is high to very high (30-90\%) while $25-28 \%$ soil 


\begin{tabular}{lll}
\hline $\begin{array}{l}\text { Environmental conditions affecting } \\
\text { degradation. Parameters }\end{array}$ & $\begin{array}{l}\text { Condition required for microbial } \\
\text { activity }\end{array}$ & $\begin{array}{l}\text { Optimum value for an oil } \\
\text { degradation }\end{array}$ \\
\hline Soil moisture & $25-28 \%$ of water holding capacity & $30-90 \%$ \\
\hline Soil pH & Aerobic, minimum air-filled pore space & $6.5-8.0$ \\
\hline Oxygen content & of $10 \%$ & C:N:P $=100: 10: 1$ \\
\hline Nutrient content & N and P for microbial growth & $20-30$ \\
\hline Temperature $\left({ }^{\circ} \mathrm{C}\right)$ & $15-45$ & Hydrocarbon 5-10\% of dry weight of \\
\hline Contaminants & Not too toxic & soil \\
\hline Heavy metals & Total content 2000 ppm & 700 ppm \\
Type of soil & & Low clay or silt content \\
\hline
\end{tabular}

Sources:Vidali,2001; Thapa et al.2012,

Table 2. Factors Influencing Microbial Activities

moisture is required since a good number of these organisms are aerobes. Again, optimal soil $\mathrm{pH}$ range for oil degradation is 6.5 to 8.0 while microorganisms require 5.5 to 8.8 .

\begin{tabular}{lllllll}
\hline \multicolumn{1}{c}{ Pollutant } & \multicolumn{5}{c}{ Time in Days } \\
\hline$((\mathrm{mg} / \mathrm{kg}))$ & 30 & 60 & 90 & 120 & 180 & LSD $_{0.05}$ \\
Chromium & 15 & 25 & 35 & 40 & 50 & 1.25 \\
Cadmium & 35 & 60 & 65 & 75 & 90 & 0.92 \\
Vanadium & 20 & 25 & 30 & 35 & 40 & 1.08 \\
Nickel & 25 & 40 & 60 & 80 & 85 & 0.96 \\
TPH & 1.8 & 2.5 & 6.5 & 7.5 & 9.0 & 0.09 \\
\hline TPH= total petroleum hydrocarbon & & & & \\
\hline (Source: Onweremadu, 2008) & \\
\hline
\end{tabular}

Table 3. Effect of composted sludge on removability of contaminants at room temperature with time (days)

There was significant reduction $(\mathrm{p}=0.05)$ in the concentration of heavy metals and total petroleum hydrocarbon with time when treated with compost manure derived from cassava sludge (Table 3).However, removability rate varied among soil pollutants over time. Higher of values of Nickel were removed between 60 and 120 days while Vanadium was steadily degraded in the soil. Generally, more values of these soil toxicants were removed in cumulative terms from soils on a long-term. But, heavy metal concentration differed between rainy and 
dry seasons prevalent in the area as well as between land use types (Table 4). There were greater variations among heavy metals in rainy season in soils affected by automobile services when compared with values in dry season in the same land use. The variation was highest in cadmium ( $\mathrm{CV}=79 \%)$, followed by Nickel ( $\mathrm{CV}=48 \%)$ and least in mercury $(\mathrm{CV}=0 \%)$.Similar trend was observed in arable soils of the area (Table 4).

\begin{tabular}{ccccc}
\hline \multicolumn{5}{c}{ Automobile wastes } \\
\hline & Heavy metal & \multicolumn{2}{c}{ Arable land } & Automobile \\
\hline & RS & DS & RS & DS \\
$\mathrm{Cd}$ & 34 & 35 & 79 & 17 \\
$\mathrm{Cr}$ & 35 & 31 & 37 & 25 \\
$\mathrm{Ni}$ & 25 & 37 & 0 & 18 \\
$\mathrm{Hg}$ & 54 & 1 & 36 & 49 \\
$\mathrm{~Pb}$ & 20 & 20 & 32 \\
\hline
\end{tabular}

$\mathrm{CV}=$ coefficient of variation in percentage, DS=dry season, RS=rainy season, $\mathrm{Cd}=$ cadmium, $\mathrm{Cr}=$ chromium, Ni=nickel, $\mathrm{Hg}=$ mercury, $\mathrm{Pb}=$ lead

(Onweremadu et al., 2007).

Table 4. Seasonal variability (CV) of heavy metal concentration $(\mathrm{mg} / \mathrm{kg})$ in soils affected by

\section{Discussion}

Exchangeable basic cations are significantly deficient in Nigerian soils particularly polluted soils. Application of composted cassava sludge will enrich these soils with basic cations thereby reducing predominance of acidic radicals. Composted cassava sludge has high content of these neutralizing cations plus appreciable values of total nitrogen which is easily leached in these tropical soils (Table 1).Again, the $\mathrm{pH}$ value of the compost (6.3) (Table1) is optimal for microbial activity in soils (Table 2 ) as most tropical crops perform optimally at ph range of 5.5 to 6.5 (Ahn,1979). Composted cassava sludge progressively removed heavy metals and total petroleum hydrocarbons in crude oil polluted soils of Nigeria (Table 3). In a similar study, Wen et al. (2002) reported a depression in the phytoavailability of copper using sludge compost but Sims and Kline (1991) observed variations in characteristics of different composts and extractants, implying compost type influences uptake and availability.in different media..It is possible sorption ability of organic materials my depend on the specific surface area of each type. However, the concentration of these toxicants vary with season as indicated in Table 4, implying that their application strategies will follow the temporal variability. It was observed that impact of composted sewage waste became significant after thirteen years in an experiment conducted by Nogueirol et al. (2013) using three rates of sludges with maize and sugar cane as test crops. 
Knowledge on the fate of heavy metals in soil-plant system is of great importance as that helps in predicting food quality especially in popular crops. Highest concentrations of heavy metals were recorded in the topmost layer of soils (Yedilar et al.,1994) and they reported that concentrations in rice leaves and grains were lower than values observed in rice roots in China.

Composted sludge has high content of organic carbon which has the capacity of absorbing organic pollutants in soil thereby reducing their solubility as demonstrated by several authors (Hernandez-Soriano et al.,2007; Stevens-Garmons et al.,2012). In addition, organic carbon inputs might enhance the soil buffer capacity. The application of slightly acidic sewage (6.3), will also affect the mobility and bioavailability of metals present in soils. The evolution of heavy metal distributions and bioavailability depended not only on total metal concentration but also on other properties such as $\mathrm{pH}$, organic matter decomposition and dissolved organic carbon (Miaomiao et al.,2009) and they reported that composting systems decreased soil $\mathrm{pH}$, soil organic matter and dissolved carbon. Their results varied between sewage sludge and swine waste. In some studies conducted in China, soil pH, soil organic matter and clay content were used to predict phytoavailability of Cadmium in paddy soils,stating that $\mathrm{pH}$ negatively correlated with cadmium cont of soils (Krebs et al.,1998). Martinez and Motto, (2000) reported that solubility availability, mobility and toxicity of heavy metals to plants increases as $\mathrm{pH}$ decreases. In a study at Suwon, Korea. Kim et al. (2009) remarked that translocation of heavy metals depended more on the variety of crop rather on soil physicochemical properties.

\section{Conclusion}

Polluted soils and soil-related natural resources can be decontaminated using living organisms including plant species classified as hyperaccumulators. Besides several microbial species can be used in bioremediation process since they can perform and efficient biodegradation activities. Efficacy in microbial degradation as well as microbial growth and activity are readily affected by edaphic characteristics like aeration, $\mathrm{pH}$, temperature, and moisture. Bioremediation ensures a minimum impact on the ecosystem, minimizing the presence of potentially toxic by-products after the process.. There are ex situ and in situ methods of bioremediation; but, most in situ bioremediation techniques are generally the most desirable options due to costeffectiveness and limited impact since they can be performed in situ; avoiding excavation and transport of contaminants. The in situtechnique proves more affordable in rural communities with higher prevalence of poverty. The main drawback is associated with long-term character of bioremediation. However, most bioremediation techniques are constrained by high specificity of operation, long period of degradation and lack of acceptable endpoints of treatment. Further research is needed to overcome the time constraint of bioremediation processes as well and to increase the spectrum of activity of microbial species to address a variety of wastes that are currently generated and entering the soil.. 


\section{Author details}

\section{Emmanuel Uzoma Onweremadu*}

Address all correspondence to: uzomaonweremadu@yahoo.com

Department Of Soil Science and Technology, Federal University Of Technology, Owerri, Nigeria

\section{References}

[1] Abou-Shanab, R. A. , J. S. Angle, T. A. Delorme, R. L.Chaney, P. Berkum, H. Moawad, K. Ghanem and H. A. Ghozlan.2003.Rhizobacterial effects on Nickel extraction from soil and uptake by Alyssum Murale. New Phytologist,158 (1): 219-224.

[2] Ahn,P.M.1979.West African soils.Oxford University Press London.

[3] Atlas, R. M .1995.Bioremediation of petroleum pollutants.Intern. Biodeteriorat. and Biodegrad.,35 (1-3):317-327.

[4] Baker, A. J. M.; Brooks, R. R. .1989.Terrestrial higher plants which hyperaccumulate metallic elements : A review of their distribution, ecology and phytochemistry.Biorecovery 1 (2): 81-126

[5] Bani,A., G. Echevarria, S. Sulçe, J. L. Morel, and A.Mullai.2007.In-situ Phytoextraction of Ni by a native population of Alyssum murale on an Ultramafic site (Albania).Plant and Soil, 293 (1) 79-89.

[6] Boyd, R. S. and T. Javre (2001). Phytoenrichement of soil content by Sebertia acuminata in New Caledonia and the concept of elemental alelopathy, South African Journ.of Sci, 97 (2): 535-538.

[7] Bremner, J. M. 1996. Nitrogen - total. In: methods of soil analysis, chemical methods (Ed. D. L. Sparks). ASA and SSSA, Madison, Wisconsin, USA pp. 1085 - 1121.

[8] Brim H, S.C. McFarlan, J.K. Fredrickson, K.W. Minton, M. Zhai, L.P. Wackett, M.J. and Daly .2000. Engineering Deinococcus radiodurans for metal remediation in radioactive mixed waste environments. Nature Biotechnol. 18 (1): 85-90.

[9] Brown M. T. and D. A. Wilkins.1985.Zinc tolerance of mycorrhizal Betula. New Phytologist, 99:101-106.

[10] Burken, J.G. 2004. Uptake and metabolism of organic compounds: Green-Liver model .In: McCutcheon, S.C.; Schnoor, J. L., Phytoremediation: Transformation and Control of Contaminants, A Wiley-Interscience Series of Texts and Monographs, Hoboken, NJ: John Wiley, p. 59, 
[11] Burken, J.; Vroblesky, D.; Balouet, J.C. 2011.Phytoforensics, Dendrochemistry, and hytoscreening: New green tools for delineating contaminants from past and present, Environ. Sci. and Technol. 45 (15): 6218-6226.

[12] Cantillo, A, and J. Calder, 1990. Reference materials for marine science. Fresewnius J. Anal. Chem. 338: 380 - 382.

[13] Chaney, R. L, M. Malik, Y. M. Li, S. L. Brown, J. S. Angle and A. J. M. Baker.1997.Phytoremediation of soil metals: Current opinion. Biotechnol., 8 ( 3): 279-284.

[14] Chará, J.G. Pedraza and N. Conde. 1999.The productive water decontamination system: A tool for protecting water resources in the tropics. Livestock Research for Rural Development11 (1):4-18

[15] Cotter-Howells, J. D, and S. Caporn.1996.Remediation of contaminated land by formation of heavy metal phosphates. Appl. Geochem., 11 ( 2):335-342.

[16] Cotter-Howells, J. D. P. E. Champness and J. M. Charnock,1999.Mineralogy of lead phosphorus grains in the roots of Agrostis capillaris L by ATEM and EXAFS.Min. Mag. (Lond), . 63 (6): 777-789.

[17] Davis, M. A., R. S. Boyd and J. H. Cane..2001.Host switching does not circumvent the Ni-based Defense of the Ni hyperaccumulator Streptanthus polygaloides (Brassicaceae), South African Journ. Sci. 97, (2) 554-557.

[18] Folke, C., S.Carpenter.B. Walker, M.Scheffer, T.Elmqvist, L.Gunderson, C.S. Holling. 2004.Regime shifts, resilience, and biodiversity in ecosystem management. Ann. Rev. Ecol. Syst, 35: 557-581.

[19] Garbisu,C. and I. Alkorta, 2001.Phytoextraction: A cost effective plant-based technology for the removal of metals from the environment," Biores. Technol., 77 (3): 229-236.

[20] Gunderson, J. J., J. D. Knight and K. C. J. van Rees.2007.Impact of ectomycorrhizal colonization of hybrid poplar on the remediation of diesel-contaminated soil. Journ. Environ. Qual. 36 (4) 927-934.

[21] Gupta, A. K. and S. Sinha, 2007.Phytoextraction capacity of the Chenopodium album L. grown on soil amended with tannery sludge, Bioresour. Technol., 98 (2): 442-446

[22] Heggo, A., J. S. Angle and R. L. Chaney.1990.Effects of vesicular arbuscular Mycorrhizal fungi on heavy metal uptake by soybeans, Soil Biol. and Biochem.,22 (6): 865-869

[23] Hernandez-Soriano M.C., Peña A. and Mingorance M.D. 2007. Retention of organophosphorous insecticides on a calcareous Mediterranean soil modified with carbonrich amendments and a surfactant. Sci. Total Environ.378: 109-113 
[24] Hendershot, W.H., H.Lalande and M.Duquette. 1993. Soil reaction and exchangeable acidity. In: Carter, M.R. (Ed.). Soil Sampling and mettods of soil analysis. Can. Soc. Soil Sci. Lewis Publishers, London. Pp. 141- 145.

[25] Kim,W.J.E.Yang. G.Jung,B.Park,S.Park.J.Kim, J.Kwon and G.Ryu.2009.Bioavailability and safety issues of heavy metals in paddy soil-rice soils continuum in Korea. National Institute of Agricultural Science and Technology,Suwon,Korea..S.K.Gupta, and R.Schulin.1998.Solubility and uptake of metals with and without liming of sludge amended soils.J.Environ.Qual.27:18-23.

[26] Lasat, M. M., M. Fuhrman, S. D. Ebbs, J. E. Cornish and L. V. Kochian 1998.Phytoremediation of radiocesium-contaminated soil: Evaluation of cesium-137 bioaccumulation in the shoots of three plant species," Journ. Environ. Qual.27 (1): 165-169.

[27] Levin, S. A. 1992. The problem of pattern and scale in ecology: The Robert H. MacArthur Award. Ecology 73 (6): 1943-1967.

[28] Martinez,C.E.and H.L.Motto.2000.Solubility of lead, zinc and copper added to mineral soils. Environ. Pollut.,107:153-158.

[29] McGrath, S. P. , F. J. Zhao and E. Lombi. 2001.Plant and rhizosphere processes involved in phytoremediation of metal contaminated soils. Plant and Soil, 232, (1): 207-214.

[30] Meagher, R.B .2000.Phytoremediation of toxic elemental and organic pollutants, Current Opinion in Plant Biology 3 (2): 153-162.

[31] Miaomiao, H,L.Wenghong, L Xinqiang, W.Donglei and T.Guangming.2009. Effect of composting process on phytotoxicity and speciation of copper, zinc and lead in sewage sludge and swine manure.Waste Manage.,29 (2): 590=597

[32] Mukred,A.M., A. A. Hamid, A. Hamzah and W.M.W, Yusoff.2008. Development of Three Bacteria Consortium for the Bioremediation of Crude Petroleum-oil in Contaminated Water, OnLine Journ. Biol. Sciences, 8 (4) 73-81.

[33] Nelson, D.W. and L.E. Sommers. 1982. Total carbon and organic matter. In: Page, A.L, R.H.

[34] Miller and D.R. Keeney (Eds.). Methods of soil analysis, part 2. Agronomy Monogr. No.9, SSSA Madison W.I. pp.539 - 579.

[35] Nogueirol,R.C.,W.J.de Melo, E.I.Bertoncini, L.Reynaldo and F Alleoni.2013.Concentrations of $\mathrm{Cu}, \mathrm{Fe}, \mathrm{Mn}$ and $\mathrm{Zn}$ in tropical soils amended with sewage sludge and composted sewage sludge.Environ. Monit. And Assess.185 (4):2929-2938.

[36] Olsen, S.R. and Sommers, L.E. 1982. In: Page, A.L; Miller, R.H. and Keeney, D.R. (eds).

[37] Methods of soil analysis, $2^{\text {nd }}$ ed. Agron. Monogr. ASA and SSSA, Madison, WI. pp. 403-430. 
[38] Olson, P. E., A. Castro, M. Joern, N. M. DuTeau, E. A. H. Pilon-Smits and K. F. Reardon.2007.Comparison of plant families in a greenhouse phytoremediation study on an aged polycyclic aromatic hydrocarbon-contaminated soil. Journ. Environ. Qual., 36:1461-1469.

[39] Onweremadu.E.U,,E.T.Eshett and G.E.Osuji.2007.Temporal variability of selected heavy metals in automobile soils.Int. Journ.Environ.Sci.Technol.,4 (1):35-41.

[40] Onweremadu.E.U.2008.Characterization and removability of priority pollutants in oil-spilled site using composted cassava sludge.Life Sci.Journ.5 (3):62-66.

[41] Polprasert, .C. 1989. Organic waste recycling, Asian Institute of Technology. Bangkok. John Wiley and Sons London. 357p.

[42] Preston. T. R. and Murgueitio .E. 1992. Strategy for sustainable livestock production in the tropics. Cali. SAREC-CIPAV. 89p.

[43] Raskin,I. and B. D. Ensley.2000.Phytoremediation of toxic Metals using plants to clean-up the environment. Wiley, New York, .

[44] Reed, S. T. and D. C. Martens. 1996. Copper and Zinc p. 703 - 722. In D. L. Sparks (ed.) methods of soils analysis. Part 3, SSSA Book Series No. 5. SSSA and ASA, Madison, WI

[45] Sambandan, K., K. Kannan and N. Raman,1992.Distribution of vesicular-arbuscular mycorrhizal fungi in heavy metal polluted soils of Tamil Nadu, India. Journ. Environ. Biol.13 : 159-167.

[46] Sims,J.S. and J.T.Kline.1991.Chemical fractionation and uptake of heavy metals in soils amended with co-composted sewage sludge.J.Environ.Qual. 20:387-395.

[47] Smith, S. E. and D. J. Read1997.Mycorrhizal symbiosis. 2nd Edition, Academic Press, London.

[48] Soil Survey Staff. 2003. Keys to soil taxonomy. Ninth edition. United States Department of Agriculture. 332 pp.

[49] Steele,M.C. and J. Pichte.1998. Ex-situ remediation of metal contaminated superfund soil using selective extractants, Journ. Environ. Eng., 124 (7): 639-645.

[50] Stevens-Garmon 2012. Sorption of emerging trace organic compounds onto wastewater sludge solids. Water Res. 45 (11):3417-3426

[51] Subramanian, M.; O. J.David, . and J. V .Shanks,. 2006.. TNT Phytotransformation pathway characteristics in Arabidopsis: Role of aromatic hydroxylamines, Biotechnol. Prog. 22 (1): 208-216.

[52] Thapa,B.,A.K.C. Kumar and A. Ghimire (2012). A review on bioremediation of petroleum hydrocarbon contaminants in soil . Kathmandu Univ. Journ. Sci. Eng.Technol., 8 ( I): 164-170. 
[53] Van Hamme, J. D., A. Singh and O. P. Ward.2003.Recent advances in petroleum microbiology. Microbiol. And Molecular Biol. Rev., 67 (4): 503-549.

[54] Vidali.M.2001. Bioremediation.:An overview. Pure Appl. Chem., 73 (7) :1163-1169.

[55] Vroblesky, D.; Nietch, C.; Morris, J. 1998.Chlorinated ethenes from groundwater in tree trunks, Environ. Sci.and Technol. 33 (3): 510-515.

[56] Wang, Q., X. Fang, B. Bai, X. Liang, P. J. Shuler and W. A. Goddard.2007.Engineering bacteria for production of rhamnolipid as an agent for enhanced oil recovery. Biotechnol. Bioeng. 8 (4): 842-853.

[57] Wen,G., T.E..Bates, S.Inanaga, R.P.Voroney,K. Hamamura and D.Curtin.2002. A yield control approach to assess phytoavailability of $\mathrm{Zn}$ and $\mathrm{Cu}$ in irradiated, composted sewage sludges and composted manures in field experiments II:Copper.Plant and Soil, 246 (2):241-248..

[58] Wenzel, W. W. and F. Jockwer,.1999.Accumulation of heavy metals grown on mineralized soils of the Austrian Alps. Environ. Pollut. 104, (1):145-155.

[59] Yedilar,A.,P. Grill.,T.Sun and.A.Kettrup.1994.Fate of heavy metals in a land treatment system irrigated with municipal waste water.Chemosphere,28 (2):375-381.

[60] Yee, D. C.,J. A. Maynard and T. K. Wood.1998.Rhizoremediation of trichloroethylene by a recombinant, rootcolonizing Pseudomonas fluorescens strain expressing toluene ortho-monooxygenese constitutively. Appl. Environ. Microbiol. 64 ( 1):112-118. 
